\section{Edycasaice

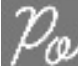

DossIÊ

\section{Editora}

Maria Inês Côrte Vitoria

PUCRS, RS, Brasil

\section{Editora Colaboradora}

Pricila Kohls dos Santos

PUCRS, RS, Brasil

\section{Equipe Editorial}

Carla Spagnolo

PUCRS, Brasil

Rosa Maria Rigo

PUCRS, Brasil

\section{ISSN 2179-8435}

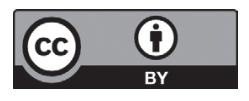

Este artigo está licenciado sob forma de uma licença Creative Commons Atribuição 4.0 Internacional, que permite uso irrestrito, distribuiçăo e reproduçăo seja corretamente citada. http://creativecommons.org/licenses/by/4.0/deed.pt BR

\title{
Hibridismo tecnológico no cotidiano da sala de aula: analisando potencialidades e limites das tecnologias
}

\author{
Technological hibridism in the classroom routine: \\ analysing possibilities and limitations of technologies
}

\author{
Fabrícia Py Tortelli Noronha ${ }^{1}$ \\ Luciana Backes ${ }^{2}$ \\ Cledes Antonio Casagrande ${ }^{3}$
}

\section{RESUMO}

O presente artigo explora o conceito de hibridismo tecnológico no cotidiano da sala de aula mediante potencialidades e limites das tecnologias analógicas (caneta e papel) e digitais (VisuAlg, Scratch e Kit Lego), no âmbito da dissertação intitulada A construção do conhecimento de algoritmos no contexto do hibridismo tecnológico: análise da prática pedagógica aplicada no IFRS, realizada no programa de Pós-Graduação em Educação, na linha de pesquisa "Culturas, Linguagens e Tecnologias na Educação". O estudo caracterizou-se como sendo do tipo estudo de caso e tem como fundamentação teórica os pressupostos da epistemologia genética de Jean Piaget. Os dados coletados foram submetidos à Técnica de Análise de Conteúdo de Bardin (2006). Para a coleta dos dados empíricos, foram apresentadas tecnologias analógicas e digitais, as quais serviram de base tecnológica para o desenvolvimento dos processos de ensino e de aprendizagem de algoritmos na disciplina de "Lógica de Programação". O contexto do hibridismo tecnológico potencializou a construção do conhecimento de algoritmos, sobretudo pela pluralidade de representação do conhecimento, contemplando

\footnotetext{
1 Professora do Ensino Básico, Técnico e Tecnológico do Instituto Federal de Educação, Ciência e Tecnologia Rio Grande do Sul, IFRS, campus Porto Alegre. Especialista em Administração de Marketing pela Ulbra. Mestre em Educação pela Universidade LaSalle - Unilasalle, na linha de pesquisa Culturas, Linguagens e Tecnologias na Educação. Doutoranda em Educação pela Unilasalle.

2 Professora titular da Universidade LaSalle - Unilasalle, Canoas, RS, no Programa de Pós-Graduação em Educação. Líder do Grupo de Pesquisa Convivência e Tecnologia Digital na Contemporaneidade COTEDIC UNILASALLE/CNPq. Pesquisadora visitante ao Centre Edgar Morin - Paris. Doutora em Educação pela UNISINOS e doutora em Science de l'éducation pela Université Lumière Lyon 2.

${ }^{3}$ Professor do PPG em Educação da Universidade LaSalle - Unilasalle, de Canoas, RS, Brasil; Doutor em Educação pela Pontifícia Universidade Católica do Rio Grande do Sul. Pós-Doutor pelo Unilasalle e Vice-Reitor dessa mesma instituição.
} 
variadas estratégias e linguagens para a aprendizagem, oportunizando o protagonismo no sujeito e atribuindo significado ao conhecimento.

Palavras-chave: Hibridismo tecnológico; Construção do conhecimento; Algoritmos; Tecnologias.

\section{ABSTRACT}

This article explores the concept of technological hybridism in classroom routine by analyzing the possibilities and limitations of analogic (pen and paper) and digital (VisuAlg, Scratch and Kit Lego) technologies, within the scope of the dissertation The construction of the knowledge of algorithms in the context of technological hybridism: analysis of pedagogical practice applied in IFRS, carried out at the Graduate Program in Education, within the research line "Culture, Languages and Technologies in Education". This study is characterized as a single case study and has as its theoretical foundation the assumptions of genetic epistemology developed by Jean Piaget. The data collected were submitted to the Bardin Technique Content Analysis (2006). For the collection of the bases empirical data, analogic and digital technologies were presented, which served as technological bases for the development of algorithm teaching and learning processes throughout the Programming Logic course. The context of technological hybridism has potentialized construction of knowledge, especially on account of the plurality in the representation of knowledge, contemplating various strategies and languages in the learning process, providing protagonism to the subject and conferring meaning to knowledge.

Keywords: Technological hybridism; Construction of knowledge; Algorithms; Technology.

\section{Introdução}

$\mathrm{D}$ esde os primórdios, a sociedade vive em constante transformação. Com o surgimento das tecnologias digitais, principalmente o computador pessoal e a internet, modificaram-se as relações pessoais e interpessoais, transformando-se e, consequentemente, a educação também foi impactada, como parte integrante dessa sociedade e inserida nesse contexto.

Nessa perspectiva de evolução, Castells (2007) chama a atenção para o conceito de 'sociedade em rede', que emerge nesse novo mundo, no qual a principal moeda deixa de ser o capital e a mão de obra, para dar lugar ao conhecimento e ao processamento da informação, por meio das tecnologias.

A inserção das tecnologias digitais na sociedade traz consigo a promessa de tempos melhores, novas oportunidades, otimização do trabalho, democratização do saber. Mas, por trás dessas novas oportunidades, há uma problemática complexa que a sociedade não consegue resolver e que vai além de trabalhos cognitivos e criativos. Uma amostra disso é a interação que proporcionam às pessoas geograficamente distantes, mas, ao mesmo tempo, 
segregam relacionamentos com pessoas tão próximas. Quer dizer, incluem e excluem diferentes classes sociais num mundo ora paralelo (que não se encontram), ora híbrido, conforme sugere Latour (1994).

No campo educativo, especialmente nos processos de ensino e aprendizagem, as transformações advindas da inserção de tecnologias digitais na sociedade são nítidas. Elas impactam os modos de socialização e os processos de subjetivação, acentuando as diferenças entre as gerações. Mudanças sempre aconteceram mas, a diferença explícita que ocorre no âmbito das transformações é que, agora são mais evidentes, rápidas e ocorrem em dimensões globais, afetando todo o tecido da sociedade e, por consequência, o ambiente escolar.

Assim, no contexto emergente do hibridismo tecnológico, há, portanto, a necessidade de repensar, de modo amplo e global, o papel da escola e, especialmente os modos como os processos de ensino e de aprendizagem são concretizados. E esse é nosso objetivo com o presente artigo, pois entendemos que o processo educativo, na forma de ações pedagógicas intencionais e planejadas, precisa estar em congruência com as transformações sociais e tecnológicas, de forma a contextualizar os conhecimentos, despertar o interesse pelo cotidiano e o desejo pela aprendizagem.

Diante disso, entendemos ser de vital importância a utilização de diferentes tecnologias no cotidiano da sala de aula, auxiliando nas necessidades dos educandos e na efetivação do complexo processo de ensino e aprendizagem.

A seguir, relataremos a experiência da pesquisa de mestrado colocada em prática. Para tanto, apresentaremos os procedimentos metodológicos utilizados na coleta e análise dos dados. Visitaremos uma série de autores, os quais utilizam o termo hibridismo nas mais variadas conjunturas, a fim de chegar a uma concepção de hibridismo tecnológico na perspectiva da ação pedagógica no processo de aprendizagem de algoritmos. Por fim, exibiremos as reflexões sobre o hibridismo tecnológico e as ações pedagógicas em sala de aula.

\section{Percurso metodológico}

Este estudo resulta da dissertação de mestrado intitulada A construção do conhecimento de algoritmos no contexto do hibridismo tecnológico: análise da prática pedagógica aplicada no IFRS, realizada no programa de Pós-Graduação em Educação, na linha de pesquisa "Culturas, Linguagens e Tecnologias na Educação". Teve como objetivo identificar e analisar as potencialidades e os limites da utilização das tecnologias analógicas (caneta e papel) e digitais (VisuAlg, Scratch e kit Lego) para a construção do conhecimento de algoritmos no contexto do hibridismo tecnológico. Do mesmo modo, investigar as contribuições para o desenvolvimento do processo de aprendizagem e a construção do conhecimento de algoritmos, bem como, refletir sobre a pluralidade de representação de conhecimentos na prática pedagógica.

Os sujeitos da pesquisa foram os educandos regularmente matriculados na disciplina de "Lógica de Programação", no ano de 2016, do curso superior de "Tecnologia em Sistemas para Internet". A disciplina contou 24 (vinte e quatro) 
alunos. Desses alunos, 19 (dezenove) estavam iniciando o curso - primeiro semestre - e, os outros 5 (cinco), eram de outros semestres e estavam repetindo a disciplina.

Realizamos um estudo de caso como forma de observação e análise do emprego das tecnologias abordadas. Segundo Gil (2010, p. 37), o estudo de caso "consiste no estudo profundo e exaustivo de um ou poucos objetos, de maneira que permita seu amplo e detalhado conhecimento". O estudo está vinculado, no Comitê de Ética da Pesquisa, ao projeto de pesquisa "Os Espaços Híbridos (geograficamente localizados e tecnologias digitais): A Presença e a Copresença nos Processos de Ensinar e Aprender" e ao Grupo de Pesquisa - Convivência e Tecnologia Digital na Contemporaneidade (COTEDIC UNILASALLE/CNPq).

Posterior a aplicação de cada tecnologia em sala de aula, foi realizado o levantamento de dados com os educandos por meio de questionários. Igualmente fizemos uso de um diário de campo, com um roteiro predefinido, no qual foram anotadas as observações proporcionadas pelas interações com os educandos, desde suas falas, angústias até reflexões, em face da construção do conhecimento associada às variadas tecnologias aplicadas.

Os dados coletados foram analisados a partir da Técnica de Análise de Conteúdo de Bardin (2006). A autora divide a análise em três etapas: pré-análise; exploração do material; e tratamento dos resultados, inferência e interpretação.

Como forma de estabelecer um primeiro contato com os conteúdos coletados, foi realizada uma leitura geral dos dados empíricos, na fase de pré-análise. A seguir, ocorreu a exploração do material, quando foram definidas as categorias, mediante unidades temáticas, isto é, unidades de palavras diretamente relacionadas a conceitos-chave desenvolvidos ao longo da pesquisa, as quais foram analisadas mediante agrupamentos que denominamos categorias. Estas, por sua vez, foram submetidas a operações de decomposição de acordo com cada conteúdo identificado.

As análises aconteceram no contexto do hibridismo tecnológico; portanto, foram realizadas na perspectiva da articulação entre as tecnologias, na coexistência e na complementariedade, mediante leituras e análises de questionários, estabelecendo relação com o diário de campo da pesquisadora.

\section{Hibridismo tecnológico e ação pedagógica}

Ao pesquisar sobre o hibridismo, evidenciou-se a diversidade de aplicações dada ao termo. Para entender melhor o contexto do hibridismo tecnológico, utilizaremos alguns autores de referência, os quais associam o hibridismo às mais variadas situações, especialmente na perspectiva do campo educacional e dos processos de ensino e aprendizagem.

Kern (2004, p. 55) afirma que se tentarmos pesquisar o termo 'hibridismo' na internet, “[...] o que mais encontraremos é a indicação de sites de biologia que muitas vezes discutem questões éticas relativas a misturas de espécies diferentes, $[\ldots]$ ". Isso se justifica porque a biologia foi uma das primeiras áreas do conhecimento que utilizou 
a palavra em suas construções teóricas. Ademais, no campo das artes, o hibridismo "[...] se constitui como um modo de fazer que pode reunir, tanto gêneros diferentes das artes visuais (pintura, escultura, etc.) quanto campos artísticos diversos (música, cinema, etc.)" (KERN, 2004, p. 57).

Canclini (1992) aborda o híbrido em uma perspectiva cultural. O autor aponta, como exemplo, em sua obra 'Culturas híbridas', a mistura da cultura indígena com a cultura de elite nos países latino-americanos, por meio do diálogo entre cultura erudita, popular e de massas.

Já Santos (2006) aborda o hibridismo em um contexto espacial. Na concepção do autor, o espaço geográfico híbrido é um conjunto indissociável de sistemas de objetos e de sistemas de ações; portanto, "o espaço geográfico deve ser considerado como algo que participa igualmente da condição do social e do físico, um misto, um híbrido. Nesse sentido não há significações independentes dos objetos" (SANTOS, 2006, p. 56).

Em sua obra 'Jamais fomos modernos', Latour (1994, p. 16) faz referência ao hibridismo como “[...] misturas entre gêneros de seres completamente novos, híbridos de natureza e cultura". Um de seus textos afirma: "Multiplicam-se os artigos híbridos que delineiam tramas de ciência, política, economia, direito, religião, técnica, ficção" (LATOUR, 1994, p. 16).

Santaella (2008, p.20) faz uma mescla do dicionário com a gramática e afirma que "[...] "hibridismo" ou "hibridez" designa uma palavra que é formada com elementos tomados de línguas diversas. Hibridação refere-se à produção de plantas ou animais híbridos." A autora faz referência também ao adjetivo híbrido como aquilo que tem origem em duas espécies diferentes - miscigenação - e ressalta o que há de comum entre todas essas formações é a "[...] mistura entre elementos diversos para a formação de um novo elemento composto." (SANTAELLA, 2008, p. 20).

Diante dos destaques dados ao emprego das palavras hibridismo, híbrido, hibridez, dentre outros associados aos diversos contextos consolidados pelos autores, e ainda reiterando Santaella (2008), neste estudo o hibridismo consiste na mistura da diversidade de tal forma que as compreendemos num contexto único, ou seja, por meio da mistura temos um único elemento.

Com um enfoque na diversidade de tecnologias, o termo hibridismo, associado à palavra tecnológico, tem o intuito de remeter à ideia de trabalhar com a mistura das tecnologias, ou como sugere Backes (2015), combinação, articulação e integração, por meio de uma prática pedagógica que oportunize a construção do conhecimento. A mistura tecnológica ocorre na associação e articulação de tecnologias de naturezas diferentes, desde as mais tradicionais, as tecnologias analógicas, até as mais contemporâneas, as tecnologias digitais.

As tecnologias fazem parte do viver e conviver dos educandos e estão imbricadas nas relações humanas. Nesse sentido, trazer o contexto do hibridismo tecnológico para o cotidiano da sala de aula, nada mais é que aproximar o 
ambiente social ao ambiente educacional, construindo o conhecimento por meio de diferentes tecnologias analógicas e digitais.

\section{O contexto do hibridismo tecnológico na construção do conhecimento de algoritmos}

Com a constante evolução tecnológica, algumas tecnologias se tornaram obsoletas, antiquadas, enquanto outras permanecem até os dias de hoje. É o caso das tecnologias analógicas caneta e papel. Na educação, pensar em ensino e aprendizagem sem lembrar da caneta e do papel é praticamente inviável. A caneta e o papel são duas das mais antigas tecnologias adotadas pela humanidade e, apesar da forte influência exercida pelos avanços tecnológicos, ainda são amplamente utilizados como recurso didático na prática escolar.

Na aprendizagem inicial de programação, desenvolver um algoritmo - programa - utilizando a caneta e o papel é uma forma de concretizar e visualizar os conceitos abstratos que envolvem as etapas de construção do algoritmo. De um modo geral, essa é a maneira mais prática e usual da experimentação concreta do raciocínio lógico, pois permite ao educando organizar e estruturar o pensamento de forma tangível, quando escreve as linhas de comandos e testa manualmente - teste de mesa ${ }^{1}$. Desse modo, foram concebidos e testados os primeiros algoritmos no caderno, com a caneta e o papel, na disciplina de "Lógica de Programação".

Já o emprego de tecnologias digitais, implica dependência do computador, uma vez que o processamento e o armazenamento da informação ocorrem por meio de dígitos binários, 0s (zeros) e 1s (uns), os bits. Como exemplos empregados na investigação temos o VisuAlg, o Scratch e o Kit Lego. Todos eles têm seu funcionamento baseado em programação, entretanto, cada qual com suas particularidades e especificidades.

O VisuAlg permite editar, interpretar e executar linhas de comandos do algoritmo em língua portuguesa. Com ele o educando não precisa efetuar o teste de mesa manualmente, o software faz a interpretação e, se for o caso, acusa os erros, embora esta última não seja sua melhor característica, pois a indicação de erros nem sempre é precisa.

No Scratch, a programação é baseada em blocos, isto é, em vez de utilizar linhas de comandos, o usuário arrasta e encaixa blocos coloridos que representam comandos e, assim, formam o algoritmo.

Esse arrastar e unir blocos faz com que o educando desvie o foco da rigidez com que a programação é tratada por meio das inúmeras linhas de códigos que compõem um programa - e, por consequência, facilita a aprendizagem.

\footnotetext{
1 O teste de mesa consiste na execução linha a linha do algoritmo com o intuito de identificar e corrigir os erros (NORONHA, 2016).
} 
Marji (2014) destaca que o Scratch tem por objetivo tornar o aprendizado da programação mais fácil e mais divertido para os iniciantes em programação.

E, por fim, com o Kit Lego "equipes de estudantes podem desenhar, construir, programar e testar robôs" (LEGO, 2008, p. 2). Com essa tecnologia, além da criação de programas no software os educandos puderam, também, testar na prática o algoritmo com as ações do robô.

Com o emprego da robótica educacional, o teste de mesa passou a ser uma etapa simplificada da programação, pois foi mais fácil identificar os erros quando o robô colocou em prática o algoritmo desenvolvido. Desse modo, propiciou uma visão mais clara, concreta e simplificada das ações dos comandos empregados no algoritmo.

Trabalhar com uma tecnologia inovadora, em um contexto de aplicação concreta, permitiu ao educando desenvolver e estruturar o raciocínio lógico mediante uma visão mais ampla e contextualizada do processo, facilitando a resolução dos algoritmos e a identificação de possíveis erros na programação.

Para compreender o processo de aprendizagem no contexto do hibridismo tecnológico desenvolvido na disciplina de "Lógica de Programação", tomamos como referência a Epistemologia Genética de Jean Piaget. Para Piaget (2007), o processo de aprendizagem consiste na compreensão de que o conhecimento é construído na interação do sujeito com o objeto do conhecimento e, nessa interação, sujeito e objeto dependem um do outro. Ou seja, o processo de aprendizagem ocorre na interação do educando com o professor, na interação do educando com os outros educandos, na interação do educando com o conhecimento (algoritmo) e na ação que o conhecimento (algoritmo) provoca no educando. São ações que transformam e modificam sujeito e objeto simultaneamente (PIAGET, 1973).

Essa situação pôde ser observada no cotidiano da sala de aula na ocorrência das interações do sujeito com o objeto do conhecimento (professora, algoritmo, colegas), no momento em que o educando assimila o conhecimento, compreendendo a ação que cada comando desempenha no algoritmo, modificando e sendo modificado, isto é, acomodando e adaptando as novas informações, atingindo o equilíbrio, melhor dizendo, o seu desenvolvimento a partir da evolução de sua inteligência. "Daí resulta que a teoria do desenvolvimento apela, necessariamente, para a noção de equilíbrio entre os fatores internos e externos ou, mais em geral, entre a assimilação e a acomodação" (PIAGET, 2011, p. 89).

Logo, a educação não se restringe mais à linearidade das relações, a centralidade do professor como detentor do saber mas sim, também, do educando, que, por meio do diálogo, pode tornar-se um colaborador na sala de aula e, portanto, sujeito da sua aprendizagem para a construção do conhecimento. 


\section{Análise e discussão dos dados: reflexões sobre as ações pedagógicas em sala de aula}

Em meio às reflexões e inferências acerca dos dados coletados por intermédio da categoria hibridismo tecnológico - evidenciada na mistura de tecnologias analógicas e digitais - mediante a unidade temática hibridismo tecnológico, foi possível evidenciar potencialidades e limites das tecnologias apontados nos questionários dos educandos e no diário de campo da pesquisadora, conforme mostra o Quadro 1, realçando aspectos e semelhanças por meio de cores.

Quadro 1. Potencialidades e limites das tecnologias

\begin{tabular}{|c|c|c|c|c|c|c|c|}
\hline \multicolumn{8}{|c|}{ Construção do Conhecimento /Processo de Aprendizagem } \\
\hline \multirow{2}{*}{\multicolumn{2}{|c|}{$\begin{array}{c}\text { Tecnologia Analógica } \\
\text { Caneta e Papel }\end{array}$}} & \multicolumn{6}{|c|}{ Tecnologias Digitais } \\
\hline & & \multicolumn{2}{|c|}{ VisuAlg } & \multicolumn{2}{|c|}{ Scratch } & \multicolumn{2}{|c|}{ Kit Lego } \\
\hline Potencialidades & Limites & Potencialidades & Limites & Potencialidades & Limites & Potencialidades & Limites \\
\hline $\begin{array}{l}\text { Esboço do } \\
\text { raciocinio lógico }\end{array}$ & $\begin{array}{l}\text { Resistência à } \\
\text { escrita }\end{array}$ & $\begin{array}{c}\text { Solidifica } \\
\text { conhecimentos }\end{array}$ & $\begin{array}{l}\text { Diferença de } \\
\text { sintaxe }\end{array}$ & $\begin{array}{l}\text { Facilita o } \\
\text { aprendizado }\end{array}$ & $\begin{array}{l}\text { Complicado, } \\
\text { muitos cliques }\end{array}$ & $\begin{array}{l}\text { Facilita o } \\
\text { aprendizado }\end{array}$ & $\begin{array}{l}\text { Diferença na } \\
\text { programação }\end{array}$ \\
\hline Fixa o conteúdo & $\begin{array}{c}\text { Dificil identificar } \\
\text { os erros }\end{array}$ & $\begin{array}{l}\text { Rápida verificação de } \\
\text { erros estimula a busca } \\
\text { pelo acerto }\end{array}$ & $\begin{array}{l}\text { Bugs, erros do } \\
\text { programa }\end{array}$ & $\begin{array}{c}\text { Visão didática do } \\
\text { algoritmo }\end{array} \mid$ & $\begin{array}{l}\text { Não aponta os } \\
\quad \text { erros }\end{array}$ & $\begin{array}{c}\text { Instiga o } \\
\text { pensamento } \\
\text { lógico }\end{array}$ & Alto Custo \\
\hline \begin{tabular}{|c|} 
Simula situação, \\
errar, apagar até \\
acertar
\end{tabular} & $\begin{array}{c}\text { Teste de mesa } \\
\text { lento e cansativo }\end{array}$ & $\begin{array}{c}\text { Teste de mesa } \\
\text { automatizado, agiliza e } \\
\text { facilita a compreensão }\end{array}$ & $\begin{array}{c}\text { Falta } \\
\text { confiabilidade } \\
\text { no teste de mesa }\end{array}$ & $\begin{array}{c}\text { Facilita o teste de } \\
\text { mesa }\end{array}$ & $\begin{array}{l}\text { Infantil para o } \\
\text { público do } \\
\text { superior }\end{array}$ & $\begin{array}{c}\text { Teste de mesa } \\
\text { rápido e concreto }\end{array}$ & $\begin{array}{l}\text { Construção do } \\
\text { robô toma } \\
\text { tempo }\end{array}$ \\
\hline $\begin{array}{l}\text { Bom para iniciar } \\
\text { na programação }\end{array}$ & $\begin{array}{c}\text { Tamanho da } \\
\text { folha do caderno } \\
\text { dificulta a } \\
\text { organização }\end{array}$ & $\begin{array}{l}\text { Aproxima da rigidez } \\
\text { dos } \\
\text { programas/Identificação } \\
\text { com o curso }\end{array}$ & & $\begin{array}{c}\text { Tira o foco da } \\
\text { sintaxe e coloca } \\
\text { no raciocinio }\end{array}$ & & $\begin{array}{c}\text { Nitida percepção } \\
\text { dos erros }\end{array}$ & \\
\hline Amigável & $\begin{array}{c}\text { Afasta do } \\
\text { ambiente de } \\
\text { desenvolvimento }\end{array}$ & Amigável & & Amigável & & \begin{tabular}{|c|} 
Fixa o que foi \\
desenvolvido em \\
sala de aula
\end{tabular} & \\
\hline $\begin{array}{l}\text { Faz o aluno } \\
\text { pensar e não ir } \\
\text { chutando até } \\
\text { acertar }\end{array}$ & & Aula mais dinâmica & & $\begin{array}{l}\text { Aula mais } \\
\text { dinâmica e } \\
\text { atraente }\end{array}$ & & $\begin{array}{l}\text { Aula mais } \\
\text { dinâmica }\end{array}$ & \\
\hline \begin{tabular}{|c|} 
Importante \\
estruturar no \\
papel para depois \\
ver o \\
funcionamento
\end{tabular} & & $\begin{array}{l}\text { Prepara } 0 \text { aluno para a } \\
\text { programação de fato }\end{array}$ & & & & $\begin{array}{l}\text { Programação } \\
\text { aplicada ao } \\
\text { mundo real }\end{array}$ & \\
\hline
\end{tabular}

Fonte: NORONHA (2016, p. 75). 
A partir das potencialidades e limites destacados, é possível inferir que o uso de tecnologias na prática pedagógica para a construção do conhecimento de algoritmos no contexto do hibridismo tecnológico apresenta pontos fortes e, também, pontos fracos, e, dependendo das circunstâncias, podem ser amenizados ou solucionados. É o caso do limite apontado na tecnologia digital VisuAlg, diferença de sintaxe. Esse limite refere-se as diferenças da linguagem utilizada com a caneta e o papel, em relação a que é utilizada no software VisuAlg. A diversidade de sintaxe encontrada na resolução de algoritmos costuma ser tão habitual, que é comum identificar na literatura o mesmo algoritmo, desenvolvido por diferentes autores, com variadas dessemelhanças na sintaxe.

Esse caso da sintaxe, apontada como limite, pode ser solucionado se o educador acolher o pseudocódigo ${ }^{2}$ utilizado pelo VisuAlg em sala de aula, com a caneta e o papel. Assim, no contexto do hibridismo tecnológico, a prática pedagógica contempla recursos distintos - analógicos e digitais - para desenvolver o raciocínio lógico, aspecto de extrema importância para os educandos que estão dando seus primeiros passos rumo à arte da programação, sem precisarem se preocupar de maneira mais intensa com as diferenças na sintaxe.

Outro limite apontado foi teste de mesa lento e cansativo, com a tecnologia analógica caneta e papel. Estabelecendo relação com a vivência da pesquisadora na disciplina de "Lógica de Programação", vem-se observando contrariedade no que diz respeito à não automação dos processos por parte dos educandos, tanto que resistência à escrita foi outro limite destacado. Importante ressaltar, em meio a esse desequilíbrio, conforme conceito de Piaget (1976), provocado pela resistência em utilizar a caneta e o papel - uma tecnologia analógica em um curso de informática, o qual pressupõe o uso de tecnologias digitais -, a tomada de consciência do educando em relação à importância de resolver algoritmos com essa tecnologia, visto que aponta como potencialidades: facilita a compreensão do conteúdo; importante para o esboço do raciocínio lógico; bom para iniciar na programação; e importante estruturar no papel para depois ver o funcionamento.

De acordo com Piaget (1977, p. 200), a tomada de consciência é "uma passagem de uma assimilação prática (assimilação do objeto a um esquema) a uma assimilação por meio de conceitos", isto é, com a tomada de consciência, o educando assimila de maneira mais aprimorada, compreendendo a conceituação do novo conhecimento por meio de construções e reconstruções - simula situação, errar, apagar até acertar -, o que lhe permitiu perceber a importância de uma tecnologia que, em um primeiro momento, causou estranhamento, perturbação e, no entanto, com base em ações cognitivas realizadas com o recurso, foi identificado como relevante para o seu processo de aprendizagem.

2 "Linguagem simples, entendida por qualquer pessoa. Dispensa conhecimento prévio sobre linguagem de programação." (NORONHA, 2016, p. 26). 
Merecem destaque as potencialidades apontadas nas tecnologias digitais Scratch: tira o foco da sintaxe e coloca no raciocínio; e no kit Lego: programação aplicada ao mundo real. Ambas proporcionam um novo olhar sobre o algoritmo e, mais que isso, ajudam a compreender os aspectos significativos para a construção do conhecimento, reconhecido igualmente por meio dos seguintes destaques: visão didática do algoritmo, facilita o aprendizado, instiga o pensamento lógico e teste de mesa rápido e concreto, como potencialidades das tecnologias em questão.

Nessa perspectiva, o educando atribuiu significado ao objeto (conhecimento) de maneira contextualizada, ou seja, o conhecimento tem um significado na realidade. Em articulação com a epistemologia genética de Jean Piaget, podemos afirmar que encontrar significado na realidade para o objeto de estudo consiste na assimilação e na acomodação da nova informação aos esquemas mentais do educando e, desse modo, retornar ao equilíbrio com os conhecimentos adaptados.

Foi indicado como um limite para o Scratch, infantil para o público do superior mas, ao mesmo tempo, também foram apontadas potencialidades importantes. Como a ordem de apresentação das tecnologias foi caneta e papel, VisuAlg, Scratch e Kit Lego, acreditamos que o emprego do Scratch no início da disciplina, quando o educando tem seu primeiro contato com a programação, afastaria essa percepção e ainda poderia contribuir com a aprendizagem por meio da ludicidade que o software pode proporcionar.

Considerando a pluralidade de representação do conhecimento, o hibridismo tecnológico teve o intuito de proporcionar diferentes perspectivas de ação e observação sobre um mesmo conhecimento, tal qual destaques dados pelos educandos no momento em que se referem a outra percepção, a outras óticas de representação do conhecimento, conforme apresentaremos no Quadro 2.

\section{Quadro 2. Palavras dos questionários e diário de campo}

\begin{tabular}{|l|}
\hline Educando U: "Permite outra visão da construção de algoritmos. \\
\hline $\begin{array}{l}\text { Educando T: "Nos ajuda a visualizar a matéria sob outras óticas e em muitas vezes nos ajuda a melhorar a } \\
\text { compreensão da matéria." }\end{array}$ \\
\hline $\begin{array}{l}\text { Diário de campo: "O contexto do hibridismo tecnológico proporcionou um processo de aprendizagem em que o } \\
\text { aluno reforçou seus conhecimentos e ele mesmo sanou suas dúvidas, por meio da experimentação de diferentes } \\
\text { formas de construção de um mesmo algoritmos. A cada nova proposta de desenvolver algoritmos com as diferentes } \\
\text { tecnologias, o educando conseguiu aprimorar seu raciocínio lógico e entender detalhes da programação que antes } \\
\text { pareciam abstratos e, em outro formato de resolução, parece que tudo ficou mais fácil de entender." }\end{array}$ \\
\hline
\end{tabular}

Fonte: NORONHA (2016, p. 81-82).

Educação Por Escrito, Porto Alegre, v. 9, n. 2, p. 270-282, jul.-dez. 2018 
Essas diferentes perspectivas de apresentação dos conhecimentos potencializaram o processo de aprendizagem, fortaleceram-se e foram complementadas a cada nova interpretação dos conteúdos produzida pelos distintos ambientes tecnológicos, em outras palavras, estabelecer relação com a diversidade de tecnologias propiciou ao educando uma vivência mais profunda dos conhecimentos no âmbito da disciplina.

No extrato do diário de campo identifica-se um processo de construção do conhecimento em que o sujeito é protagonista da sua aprendizagem. Ainda que o contexto do hibridismo tecnológico seja configurado nas interações entre os sujeitos para a construção do conhecimento no coletivo, a interação foi evidenciada entre o sujeito e o objeto do conhecimento no momento em que o educando age para obter as respostas aos seus questionamentos, resolvendo as suas dúvidas por intermédio de um contexto híbrido, no qual as tecnologias se misturam e proporcionam significados aos conhecimentos no âmbito da disciplina.

\section{Considerações finais}

Por meio do contexto do hibridismo tecnológico revelado na mistura, articulação e integração de tecnologias analógicas e digitais, foi possível destacar potencialidades e limites das tecnologias exploradas. Os limites não excluíram as tecnologias e, tampouco as classificaram como inadequadas, mas apontaram para alternativas de integração às outras tecnologias, na perspectiva da coexistência.

De acordo com Backes e Ratto (2016), o contexto do hibridismo é configurado por ações realizadas no viver diário, em que são misturados naturalmente diferentes recursos. Nesse sentido, foi evidenciada essa compreensão nos educandos quando abordaram as distintas tecnologias como relevantes para o seu processo de aprendizagem, de tal maneira que não houve a preocupação em identificar qual tecnologia contribui para uma determinada aprendizagem, todas estavam imbricadas num único processo - a aprendizagem.

No âmbito da disciplina de "Lógica de Programação", o hibridismo emergiu de maneira natural; um exemplo disso aconteceu quando o educando enviava uma atividade pelo ambiente virtual de aprendizagem - AVA - e, ao mesmo tempo, encaminhava um e-mail ao professor, avisando que havia postado a atividade. Esse contexto de usar múltiplos recursos é uma forma de olhar para esse cotidiano e identificar que as pessoas organizam-se assim, e isso pode ser explorado em sala de aula, de modo que o cotidiano do educando seja cada vez mais análogo ao ambiente acadêmico.

O propósito da investigação foi apresentar os novos conhecimentos aos educandos apoiados em variadas tecnologias - hibridismo tecnológico. Essa oferta de possibilidades de aprendizagem promoveu uma prática pedagógica com pluralidade de representações do conhecimento por meio de textos, de sons, de imagens, de animações e da 
robótica. Em vista disso, o educando experienciou uma visão mais didática dos conhecimentos, a qual oportunizou o protagonismo de suas ações na busca pela solução dos algoritmos (problemas).

Observou-se que mudanças na prática pedagógica, como alterar a ordem de apresentação das tecnologias e empregar a sintaxe utilizada no software VisuAlg, também no caderno, com a caneta e o papel, proporcionariam ao educando, iniciante em programação, formas distintas de aprendizagem, analógica e digital, que se complementariam sem ter preocupação com as diferenças da sintaxe.

Um fato que chamou a atenção foi a tomada de consciência dos educandos em relação a importância das tecnologias analógicas na construção do conhecimento de algoritmos, as quais inicialmente sofreram certa resistência em relação a sua utilização, por se tratar de um curso superior na área da informática.

Outra importante constatação foi em relação ao Scratch e ao Kit Lego, ambos revelaram uma nova perspectiva sobre as etapas de construção do algoritmo, possibilitando significado contextualizado no conhecimento.

Assim, o contexto do hibridismo tecnológico, com o apoio de tecnologias analógicas e digitais, vem ao encontro dos anseios e necessidades do meio educacional de modo a promover mudanças e potencializar o processo de ensino e aprendizagem, aproximando cada vez mais a sala de aula do cotidiano do educando, o qual é imerso em tecnologias.

O presente trabalho foi realizado com apoio da Coordenação de Aperfeiçoamento de Pessoal de Nível Superior - Brasil (CAPES) - Código de Financiamento 001.

\section{Referências}

BACKES, Luciana; RATTO, Cleber G. The tribes in the context of the digital technological hybridism: the constitution of the virtual digital acquaintanceship. ETD: Educação Temática Digital, v. 18, p. 564-579, 2016.

BARDIN, Laurence. Análise de conteúdo. São Paulo: Edições 70, 2006.

CANCLINI, Néstor García. Culturas híbridas: estrategias para entrar y salir de la modernidad. Buenos Aires: Sudamericana, 1992.

CASTELLS, Manuel. A era da informação: economia, sociedade e cultura. 10. ed. São Paulo: Paz e Terra, 2007.

GIL, Antonio Carlos. Como elaborar projetos de pesquisa. 5. ed. São Paulo: Atlas, 2010

KERN, Daniela. O conceito de hibridismo ontem e hoje: ruptura e contato. MÉTIS: história \& cultura, v. 3, n. 6, p. 53-70, jul./dez. 2004. Disponível em: <http://www.ucs.br/etc/revistas/index.php/metis/article/view/1158/797>. Acesso em: 19 jul. 2018.

LATOUR, Bruno. Jamais fomos modernos: ensaio de antropologia simétrica. Tradução Carlos Irineu da Costa. Rio de Janeiro. Ed. 34, 1994.

Educação Por Escrito, Porto Alegre, v. 9, n. 2, p. 270-282, jul.-dez. 2018 
LEGO, Mindstorms Education. Manual do NXT 2.0. 2008. [PDF].

MARJI, Majed. Aprenda a programar com Scratch. São Paulo: Novatec, 2014.

NORONHA, Fabrícia P T. A construção do conhecimento de algoritmos no contexto do hibridismo tecnológico: análise da prática pedagógica aplicada no IFRS. Dissertação (Mestrado em Educação) - Centro Universitário La Salle, Canoas, 2016.

PIAGET, Jean. Estudos sociológicos. Rio de Janeiro: Forense, 1973.

PIAGET, Jean. A equilibração das estruturas cognitivas: problema central do desenvolvimento. Rio de Janeiro: Zahar, 1976.

PIAGET, Jean. A tomada de consciência. São Paulo: Melhoramentos, 1977.

PIAGET, Jean. Epistemologia genética. Tradução Álvaro Cabral. 3. ed. São Paulo: Martins Fontes, 2007.

PIAGET, Jean. Seis estudos de Piaget. Tradução Maria Alice Magalhães D’Amorim e Paulo Sérgio Lima Silva. 25. ed. Rio de Janeiro: Forense Universitária, 2011.

SANTAELLA, Lucia. A ecologia pluralista das mídias locativas. Revista Famecos, Porto Alegre, n. 37, 2008. Disponível em: <http:// revistaseletronicas.pucrs.br/ojs/index.php/revistafamecos/article/view/4795>. Acesso em: 22 jul. 2018.

SANTOS, Milton. A natureza do espaço: técnica e tempo, razão e emoção. 4. ed. São Paulo: Editora da Universidade de São Paulo, 2006. Disponível em: <http://bibliodigital.unijui.edu.br:8080/xmlui/bitstream/handle/123456789/1799/A\%20natureza\%20do\%20 Espa\%C3\%A7o.pdf?seq\%3E.\%20Acesso\%20em:\%2020\%20fev.\%202017>. Acesso em: 20 jul. 2018.

Recebido em: julho/2018

Aceito em: outubro /2018

Endereço para correspondência:

Fabrícia Py Tortelli Noronha <fabricia.noronha@poa.ifrs.edu.br>

Rua Cabral 30/501

90420-120, Porto Alegre, RS, Brasil 